Check for updates

Cite this: Mater. Adv., 2020, 1,3572

Received 27th July 2020 , Accepted 13th November 2020

DOI: 10.1039/d0ma00546k

rsc.li/materials-advances

\section{Superior anchoring effect of a Cu-benzenehexathial MOF as an aluminium-sulfur battery cathode host $\dagger$}

\author{
Preeti Bhauriyal (D) and Biswarup Pathak (D) *
}

\begin{abstract}
The poor reversibility and short lifespan of next generation Al-S batteries can be effectively overcome by opting for a cathode host able to trap sulfur and Al polysulfide species. In this work, with the help of density functional theory (DFT) calculations, a 2D Cu-benzenehexathial (Cu-BHT) metal organic framework (MOF) has been proposed as an excellent potential cathode host for $\mathrm{Al}-\mathrm{S}$ batteries as compared to carbonaceous hosts such as graphene. The favourable electrical conductivity of the Cu-BHT MOF eliminates the insulating nature of most sulfur-based electrodes and is helpful in supporting the cathode charge/discharge processes. The results of a binding study show that while graphene has low binding energies $(-0.76$ to $-0.88 \mathrm{eV})$ towards $\mathrm{Al}$ polysulfides, the $\mathrm{Cu}-\mathrm{BHT}$ MOF exhibits improved binding to Al polysulfides $(-1.11$ to $-3.56 \mathrm{eV})$ because of the presence of copper and sulfur, which results in increased charge transfer to the Al polysulfides. The synergic dual interactions based on the Al-S (of the sulfur host) bond and $\mathrm{S}$ (of the Al polysulfide)-Cu bond also lead to a uniform deposition of insoluble $\mathrm{Al}_{2} \mathrm{~S}_{3}$ over the $\mathrm{Cu}$-BHT surface, improving the utilization of the active cathode host. This leads to the incorporation of $45.81 \mathrm{wt} \%$ sulfur in the $\mathrm{Cu}$-BHT monolayer host, higher than that of the experimentally reported SaHKUST-1-C cathode host (34 wt\%) for Al-S batteries. Moreover, it is also observed that the Al polysulfide binding is much stronger than their interaction with the electrolytes, thus decreasing the overall dissolution of Al polysulfides into the electrolyte and improving the net cycling performance in Al-S batteries. With these desirable properties, it is expected that the $\mathrm{Cu}-\mathrm{BHT}$ MOF can be used as a promising anchoring cathode host compared to graphene in $\mathrm{Al}-\mathrm{S}$ batteries.
\end{abstract}

\section{Introduction}

The high abundance of aluminium (Al) in the earth's crust, the high volumetric (8.05 $\mathrm{A} \mathrm{h} \mathrm{cm}^{-3}$ ) and gravimetric capacity (2.98 $\mathrm{A} \mathrm{h}^{-1}$ ) associated with the $3 \mathrm{e}^{-}$redox reaction and its excellent safety make $\mathrm{Al}$ one of the most advantageous elements and $\mathrm{Al}$-metal based batteries the future of leading energy storage systems. ${ }^{1-3}$ The use of ionic liquid-based electrolytes has increased the efficiency and stability of $\mathrm{Al}$ batteries via increasing reversible $\mathrm{Al}$ deposition/stripping with high Coulombic efficiency and thus has become the obvious choice for current Al batteries. ${ }^{4,5}$ These ionic liquid based Al batteries have been proposed to work via two distinctive reversible energy storage mechanisms depending upon the nature of the cathode materials: one is intercalation reaction and the other is conversion reaction. As the chloroaluminate ionic

Discipline of Chemistry, Indian Institute of Technology (IIT) Indore, Indore, Madhya Pradesh 453552, India. E-mail: biswarup@iiti.ac.in

$\dagger$ Electronic supplementary information (ESI) available. See DOI: 10.1039/ d0ma00546k liquid electrolyte consists of $\mathrm{Al}$ ions in the form of both cation and anions, both $\mathrm{Al}^{3+}$ and $\mathrm{AlCl}_{4}{ }^{-}$can undergo intercalation in rocking chair type $\mathrm{Al}$ batteries ${ }^{6-16}$ and $\mathrm{Al}$ dual-ion batteries, ${ }^{17-30}$ respectively. The rocking chair $\mathrm{Al}$ batteries have been reported to exhibit high capacity $\left(\sim 300 \mathrm{~mA} \mathrm{~h} \mathrm{~g}^{-1}\right)$ but are limited by their small cycle life ( $<20$ cycles), coulombic efficiency and cell voltage range $(\sim 0.6 \mathrm{~V})$, whereas $\mathrm{Al}$ dual-ion batteries can deliver higher voltages $(\sim 2.0 \mathrm{~V})$ with fast charge/discharge rates, but they have low storage capacity $\left(<120 \mathrm{~mA} \mathrm{~h} \mathrm{~g}{ }^{-1}\right)$ and involve large volume expansion due to the involvement of a large sized anion, ${ }^{31}$ which can cause irreversible damage to the battery. On the other hand, the conversion reaction mechanism has been reported in the case of $\mathrm{Ni}$ - and Fe-based sulfides, ${ }^{32-35}$ which can hold higher storage capacities for the initial charge/ discharge cycles, but they abruptly drop during long term usage due to destruction of the cathode lattice with continuous charge/discharge cycles. ${ }^{33}$ Also, low conductivity is a big obstacle in the application of these conversion based $\mathrm{Al}$ batteries. However, sulfur shows quite good advantages when used as a conversion cathode as it can undergo multi-electron transfer during electrochemical reactions to provide a high specific 
capacity of $1675 \mathrm{~mA} \mathrm{~h} \mathrm{~g}^{-1}$ and it is light-weight. Sulfur cathodes have been quite well-explored in $\mathrm{Li}-\mathrm{S},{ }^{36-39} \mathrm{Na}-\mathrm{S},{ }^{40,41}$ and $\mathrm{Mg}-\mathrm{S}^{42,43}$ batteries but the field of $\mathrm{Al}-\mathrm{S}$ batteries is still very new. At present, limited numbers of studies ${ }^{44-49}$ have been reported for non-aqueous electrolyte-based $\mathrm{Al}-\mathrm{S}$ batteries after the initial report of a successful demonstration of a primary $\mathrm{Al}-\mathrm{S}$ battery in $2015 .^{44}$ The involved charge/discharge processes were observed to follow the given reaction mechanism:

$$
\begin{gathered}
\text { Anode: } 2 \mathrm{Al}+14 \mathrm{AlCl}_{4}{ }^{-} \leftrightarrow 8 \mathrm{Al}_{2} \mathrm{Cl}_{7}^{-}+6 \mathrm{e}^{-} \\
\text {Cathode: } 8 \mathrm{Al}_{2} \mathrm{Cl}_{7}^{-}+6 \mathrm{e}^{-}+3 \mathrm{~S} \leftrightarrow \mathrm{Al}_{2} \mathrm{~S}_{3}+14 \mathrm{AlCl}_{4}^{-} \\
\text {Overall: } 2 \mathrm{Al}+3 \mathrm{~S} \leftrightarrow \mathrm{Al}_{2} \mathrm{~S}_{3}
\end{gathered}
$$

In order to improve battery efficiency, studies have either focused on the development of the cathode host material, such as by employing an activated carbon cloth/sulfur composite, ${ }^{45}$ or constructing a cathode matrix by dispersing a sulfur/ $\mathrm{Al}[\mathrm{EMI}] \mathrm{Cl}_{4}$ slurry onto free-standing carbon nanofiber (CNF) paper and coating of the single-wall carbon nanotube paper on the separator to slow down the diffusion of polysulfide. ${ }^{46}$ Or, by using a lithium-ion ( $\mathrm{Li}^{+}$-ion)-mediated ionic liquid electrolyte. ${ }^{47}$ However, these room-temperature $\mathrm{Al}-\mathrm{S}$ batteries were still observed to either show extremely poor reversibility or suffer from a sluggish electrochemical kinetics due to the lack of a suitable sulfur cathode host. In this regard, very recently, a composite of $\mathrm{S}$ on a carbonized Hong Kong University of Science and Technology-1 (HKUST-1) matrix (S@HKUST-1-C) was reported for $\mathrm{Al}-\mathrm{S}$ batteries, ${ }^{48}$ which maintained a reversible capacity of $600 \mathrm{~mA} \mathrm{~h} \mathrm{~g}^{-1}$ at the 75 th cycle and a reversible capacity of $460 \mathrm{~mA} \mathrm{~h} \mathrm{~g}{ }^{-1}$ at the 500th cycle with a Coulombic efficiency of $\sim 95 \%$. The improved efficiency of this battery was credited to the presence of $\mathrm{Cu}$ in the electrochemical process that formed an ionic cluster with polysulfide that facilitated the electrochemical reaction and improved the reversibility of $\mathrm{S}$ cathode during charging/discharging process in Al-S battery. Additionally, $\mathrm{Cu}$ increases the electron conductivity at the HKUST-1-C/S interface. Such Cu-based metal organic frameworks (MOFs) have also been explored for the development of more efficient Li-S batteries, both experimentally and theoretically. $^{50-53}$ Therefore, for the effective development of Al-S batteries, it is necessary to take inspiration from more developed $\mathrm{Li}-\mathrm{S}$ batteries as Al-S batteries may also follow a similar kind of working mechanism. Moreover, it is also important to investigate the reason behind the superior anchoring effect of $\mathrm{Cu}$-metal based materials compared to the other experimentally studied carbonaceous host materials in $\mathrm{Al}-\mathrm{S}$ batteries.

Therefore, in this study, we have investigated a twodimensional (2D) copper-based MOF (Cu-BHT) monolayer by means of density functional theory (DFT) computation to be used as a potential cathode support material in Al-S batteries, ${ }^{54}$ which has been recently synthesized by connecting benzenehexathial (BHT) ligands with $\mathrm{Cu}$ ions in an extremely dense fashion. To investigate how a MOF could act as a better cathode host than the experimentally reported carbon-based cathode hosts, we have carried out a comparative study of the Cu-BHT monolayer MOF with respect to graphene, a representative of the carbonaceous hosts. We have analysed the corresponding cathode systems on the basis of the detailed binding characteristics of sulfur and Al polysulfides, electronic properties, electrolyte interactions and $\mathrm{Al}$ polysulfide deposition behaviour. Our results show that the $\mathrm{Cu}-\mathrm{BHT}$ MOF could be a promising cathode host for use in Al-S batteries.

\section{Computational details}

Density functional theory (DFT) as implemented in the Vienna $\mathrm{Ab}$ initio Simulation Package (VASP) was used to perform the calculations. $^{55-58}$ All geometry optimization and electronic property calculations were performed using the PerdewBurke-Ernzerhof (PBE) functional of the generalized gradient approximation (GGA). ${ }^{59,60}$ The interactions between ion cores and valence electrons were treated by employing the projector augmented-wave (PAW) method. ${ }^{61,62}$ The plane wave cut-off energy was fixed to $470 \mathrm{eV}$ and the total energy was converged to $10^{-5} \mathrm{eV}$. To optimize the structures, the atomic positions were fully relaxed until the Hellmann-Feynman forces on all atoms were smaller than $0.01 \mathrm{eV} \AA^{-1}$. Moreover, all the structure optimizations were carried out using van der Waals corrected density functional theory (DFT-D3) to overcome the deficiencies of DFT in treating dispersion interactions. ${ }^{63} \mathrm{~A} 2 \times 2 \times 1$ supercell of Cu-BHT monolayer and $7 \times 7 \times 1$ supercell of graphene having the lattice parameters $a=b=17.51 \AA$ and $a=b=17.27 \AA$, respectively, were used for the calculations and the Brillouin zone was represented by a Monkhorst- $k$-point grid of $5 \times 5 \times 1$ for both systems. To avoid periodic image interaction between the two nearest neighbour unit cells, the vacuum was set to $20 \AA$ in the $z$-direction.

\section{Results and discussion}

3.1. Binding characteristics of sulfur (S8) and Al polysulfides $\left(\mathrm{Al}_{2} \mathrm{~S}_{x}\right)$ on the Cu-BHT MOF and graphene

It has been observed that in Al-S batteries, the charging and discharging processes proceed through the formation of $\mathrm{Al}$ polysulfide intermediates, as given by eqn (4) and (5),

$$
\begin{gathered}
\left(\frac{1}{8}\right) \mathrm{S}_{8}+\left(\frac{1}{3}\right) \mathrm{e}^{-} \rightarrow\left(\frac{1}{6}\right) \mathrm{S}_{6}^{2-} \\
\left(\frac{1}{6}\right) \mathrm{S}_{6}{ }^{2-}+\left(\frac{2}{x}-\frac{1}{3}\right) \mathrm{e}^{-} \leftrightarrow\left(\frac{1}{x}\right) \mathrm{S}_{x}^{2-}(1 \leq x<6)
\end{gathered}
$$

These Al polysulfide molecules can be represented with the formula unit of $\mathrm{Al}_{2} \mathrm{~S}_{x}$. Therefore, to study the binding behaviour of these $\mathrm{Al}$ polysulfides on the $\mathrm{Cu}-\mathrm{BHT}$ monolayer and graphene, we have to first find the stable structures of the set of S-containing species, $\mathrm{Al}_{2}\left(\mathrm{~S}_{6}\right)_{3}$ or $\mathrm{Al}_{2} \mathrm{~S}_{18}, \mathrm{Al}_{2}\left(\mathrm{~S}_{4}\right)_{3}$ or $\mathrm{Al}_{2} \mathrm{~S}_{12}$, $\mathrm{Al}_{2}\left(\mathrm{~S}_{2}\right)_{3}$ or $\mathrm{Al}_{2} \mathrm{~S}_{6}$, and $\mathrm{Al}_{2}(\mathrm{~S})_{3}$ or $\mathrm{Al}_{2} \mathrm{~S}_{3}$ along with $\mathrm{S}_{8}$. Out of all the possible structures studied, the most stable structures are presented in Fig. 1a. 

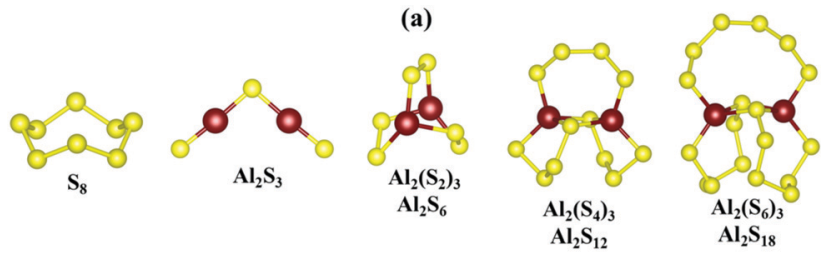

(b)

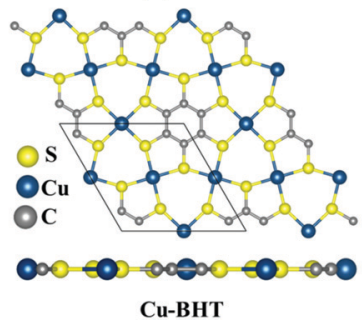

(c)

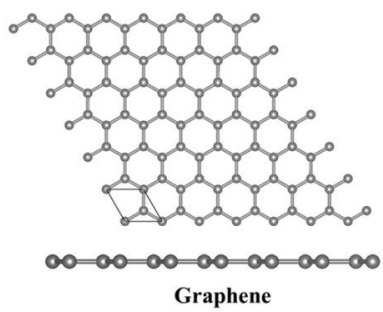

Fig. 1 (a) Most stable molecular structures of $\mathrm{S}_{8}$ and $\mathrm{Al}_{2} \mathrm{~S}_{x}(x=3,6,12$ and 18). Top and side views of the fully optimized structure of the (b) $\mathrm{Cu}$-BHT and (c) graphene monolayer surfaces.

The $\mathrm{S}_{8}$ molecule stabilizes in its most stable allotrope form at room temperature, which is a $3 \mathrm{D}$ crown like orthorhombic $\alpha-S_{8}$ structure, whereas $\mathrm{Al}_{2} \mathrm{~S}_{3}$ prefers to form a planar bent structure compared to the linear structure with the $\mathrm{S}$ atom taking the centre position with side S-Al-S and centre Al-S-Al bond angles of $179.9^{\circ}$ and $100^{\circ}$, respectively, which is in close accordance with a previous study $\left(179.2^{\circ}\right.$ and $101.7^{\circ}$, respectively). ${ }^{64,65}$ For higher order $\mathrm{Al}_{2} \mathrm{~S}_{x}$ with more $\mathrm{S}$ atoms, the $3 \mathrm{D}$ cluster shapes are more stable compared to the $2 \mathrm{D}$ chains with $\mathrm{Al}$ or $\mathrm{S}$ atoms at the terminal ends, and the cluster shape can effectively avoid the dangling bonds observed in $\mathrm{Al}_{2} \mathrm{~S}_{3}$ and contribute to the structure stability. Similar results have also been observed for higher order Li polysulfides in $\mathrm{Li}-\mathrm{S}$ batteries. ${ }^{66}$ On closer observation, we found that the $S$ atoms in these $\mathrm{Al}_{2} \mathrm{~S}_{x}$ molecules are not all equivalent in their binding nature, and the S-S and $\mathrm{Al}-\mathrm{S}$ bond lengths fall in the ranges of 2.02-2.14 $\AA$ and 2.18-2.38 , respectively (Fig. S1, ESI $\dagger$ ). Also, as the size of $\mathrm{Al}_{2} \mathrm{~S}_{x}$ molecule increases, the average Al-S bond length increases from $\mathrm{Al}_{2} \mathrm{~S}_{3}(2.09 \AA)$ to $\mathrm{Al}_{2} \mathrm{~S}_{18}(2.27 \AA)$, which could lead to the easy dissociation of the Al-S bond in higher order $\mathrm{Al}_{2} \mathrm{~S}_{x}$ molecules compared to lower order $\mathrm{Al}$ polysulfides. This could be one of the reasons for the irreversibility observed in the charging process in Al-S batteries, which involves the conversion of lower order to higher order $\mathrm{Al}_{2} \mathrm{~S}_{x} \cdot{ }^{45,46}$

The Cu-BHT monolayer possesses a hexagonal planar structure, where the $\mathrm{Cu}$ atoms and BHT are connected together by $\mathrm{Cu}-\mathrm{S}$ covalent bonds $(2.28 \AA)$, as shown in Fig. $1 \mathrm{~b}$. Our optimized lattice constant of $8.76 \AA$ is in good agreement with the previous reported values $(8.76 \AA$ and $8.80 \AA) .{ }^{54,67}$ The monolayer of the $\mathrm{Cu}-\mathrm{BHT}$ MOF has an intrinsic metallic nature mainly contributed by the electronic states of C 2p, S 3p, and $\mathrm{Cu} 3 \mathrm{~d}$ orbitals at the Fermi level and it is dynamically stable. ${ }^{68}$ This metallic characteristic of the Cu-BHT MOF could be quite beneficial in improving the rate performance of $\mathrm{Al}-\mathrm{S}$ batteries. The graphene monolayer optimized for the comparative study is also shown in Fig. 1c with lattice parameters $(a=b=2.46 \AA$ ) in good accordance with the experimental data for graphite. ${ }^{69,70}$

To investigate the reason behind the poor performance of carbon based cathode hosts for Al-S batteries, we have systematically compared the binding behaviour of $\mathrm{S}_{8}$ and the corresponding $\mathrm{Al}_{2} \mathrm{~S}_{x}$ molecules on a graphene surface as well as on the Cu-BHT MOF. Various initial structures of $\mathrm{S}_{8}$ and $\mathrm{Al}_{2} \mathrm{~S}_{x}$ molecules were investigated at possible binding sites on both $\mathrm{Cu}-\mathrm{BHT}$ and graphene monolayers and the corresponding binding energies were calculated using the following equation:

$$
E_{\text {Binding }}=\left(E_{\text {Host }+\mathrm{M}}-E_{\text {Host }}-E_{\mathrm{M}}\right)
$$

where $E_{\mathrm{Host}+\mathrm{M}}$, and $E_{\mathrm{Host}}$ are the total energies of the Cu-BHT MOF or graphene monolayer with and without $\mathrm{S}_{8}$ or $\mathrm{Al}_{2} \mathrm{~S}_{x}$ molecules, respectively. $E_{\mathrm{M}}$ is the total energy of an isolated $\mathrm{S}_{8}$ or $\mathrm{Al}_{2} \mathrm{~S}_{x}$ molecule. Here, a higher negative value of binding energy means a more favourable binding of the corresponding molecule. The plot of the corresponding binding energies including the contribution from the van der Waals functional for both $\mathrm{Cu}-\mathrm{BHT}$ and graphene monolayers is presented in Fig. 2a. And, the most stable binding configurations of $\mathrm{S}_{8}$ or $\mathrm{Al}_{2} \mathrm{~S}_{x}$ molecules on the $\mathrm{Cu}-\mathrm{BHT}$ and graphene monolayers are presented in Fig. 2c and d, respectively.

From the binding energy plot shown in Fig. 2a, we observed that graphene shows quite low binding affinity towards $\mathrm{S}_{8}$ $(-0.76 \mathrm{eV})$ and $\mathrm{Al}_{2} \mathrm{~S}_{x}$ molecules $(-0.83$ to $-0.87 \mathrm{eV})$ with very little variation. Whereas, for the Cu-BHT MOF, the binding strength remarkably increased, and, in contrast to the graphene, the binding energy was not constant but increased from $\mathrm{S}_{8}(-1.11 \mathrm{eV})$ to the $\mathrm{Al}_{2} \mathrm{~S}_{x}$ molecules, having a maximum value $(-3.56 \mathrm{eV})$ for $\mathrm{Al}_{2} \mathrm{~S}_{3}$. Our results reveal that the binding energy of $\mathrm{Al}_{2} \mathrm{~S}_{x}$ molecules varies in the range of -1.44 to $-3.56 \mathrm{eV}$ and this stronger binding strength for lower order Al polysulfides could be because of the closer binding approach of the optimized structures forming $\mathrm{Al}-\mathrm{S}_{\mathrm{Cu}-\mathrm{BHT}}(\mathrm{S}$ of $\mathrm{Cu}-\mathrm{BHT})$ and $\mathrm{Cu}-\mathrm{S}_{\mathrm{M}}$ ( $\mathrm{S}$ of the $\mathrm{Al}_{2} \mathrm{~S}_{x}$ molecule) bonds, as shown on the "with vdW" side in Fig. 2c. This overall increase in the binding strength on the Cu-BHT monolayer compared to graphene indicates its improved anchoring effect as a cathode host in Al-S batteries.

Further, to get more valuable insights into the anchoring effects of the Cu-BHT MOF and graphene, we evaluated the contribution of the physisorption (given by the vdW interactions) and chemisorption to the net binding strengths of $\mathrm{S}_{8}$ and $\mathrm{Al}_{2} \mathrm{~S}_{x}$ molecules. The percentage ratio of the vdW interaction in the overall binding strength can be calculated using $r=\left(\frac{E_{\mathrm{b}}^{\mathrm{vdW}}-E_{\mathrm{b}}^{\text {without-vdW }}}{E_{\mathrm{b}}^{\mathrm{vdW}}}\right)$, where $E_{\mathrm{b}}^{\mathrm{vdW}}$ and $E_{\mathrm{b}}^{\text {without-vdw }}$ are the binding energies with and without van der Waals corrections. Fig. $2 \mathrm{~b}$ shows the variation in the van der Waals contributions for the binding of $\mathrm{S}_{8}$ and other $\mathrm{Al}_{2} \mathrm{~S}_{x}$ molecules on graphene and $\mathrm{Cu}$-BHT monolayers. For graphene, the physisorption dominates the whole process of binding, with the maximum for $\mathrm{S}_{8}$ and the higher order $\mathrm{Al}_{2} \mathrm{~S}_{18}$ molecule, then $\mathrm{Al}_{2} \mathrm{~S}_{12}$ (85-87\%), and reducing to $78 \%$ for the lower order $\mathrm{Al}_{2} \mathrm{~S}_{6}$ and $\mathrm{Al}_{2} \mathrm{~S}_{3}$ systems. From this, we can conclude that the physisorption 
(a)

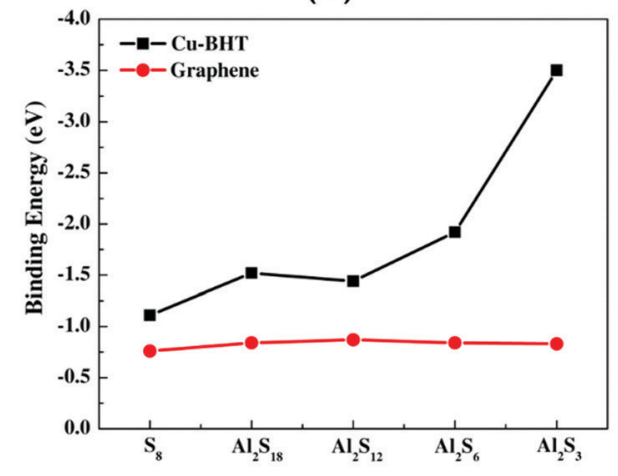

(c)
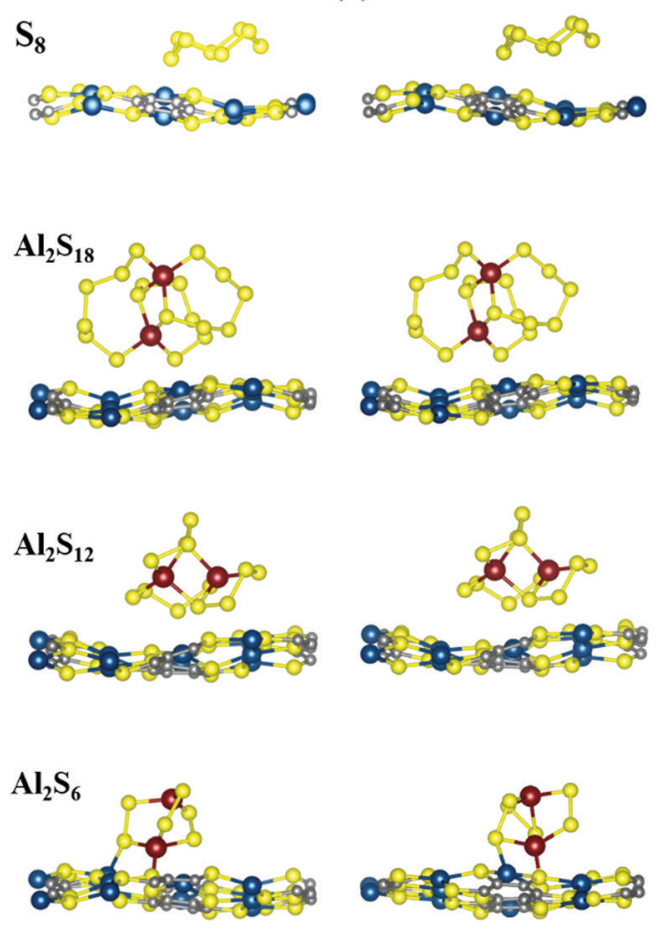

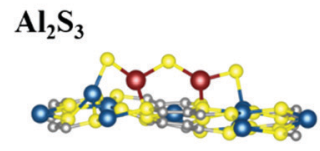

With vdW

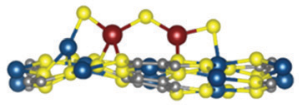

Without vdW

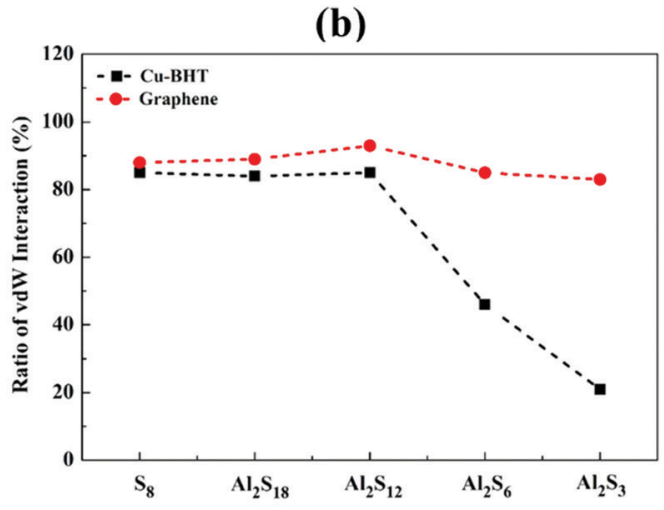

(d)
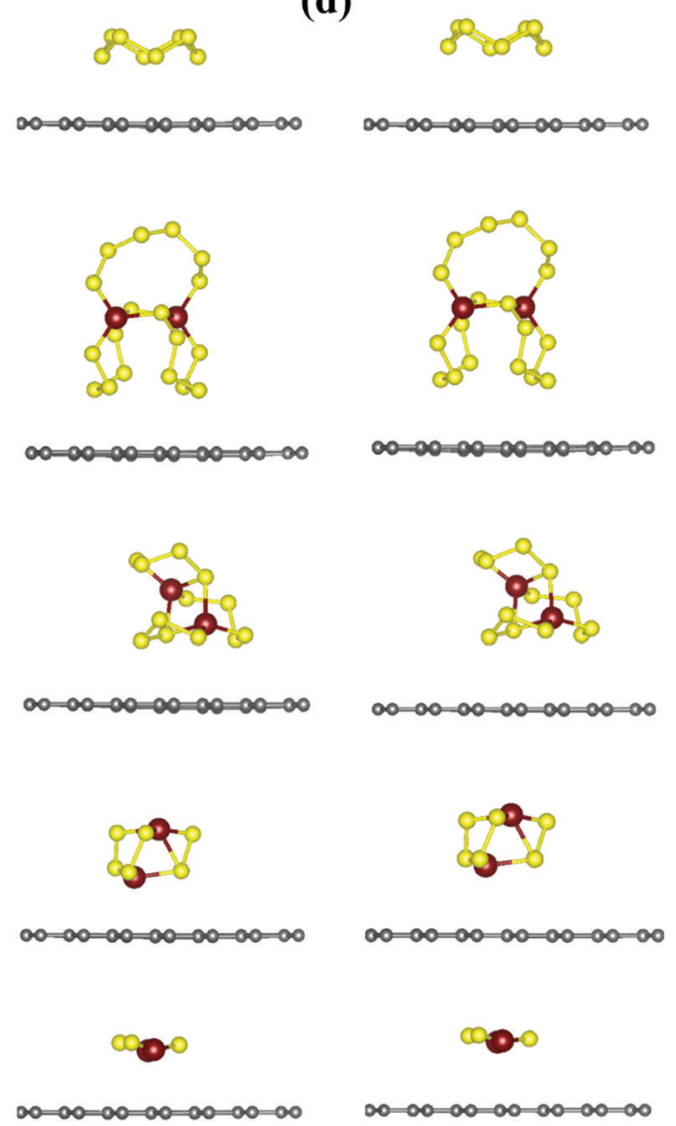

With vdW

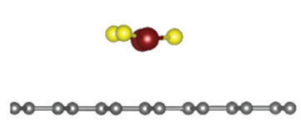

Without vdW

Fig. 2 (a) Binding energies for $\mathrm{S}_{8}$ and $\mathrm{Al}_{2} \mathrm{~S}_{x}(x=3,6,12$, and 18) on $\mathrm{Cu}-\mathrm{BHT}$ and graphene monolayers, and (b) the corresponding ratio ( $r \%$ ) for vdW interaction for the $\mathrm{Cu}-\mathrm{BHT}$ and graphene monolayers. Optimized conformations of $\mathrm{S}_{8}$ and $\mathrm{Al}_{2} \mathrm{~S}_{x}(x=3,6,12$, and 18$)$ on the (c) Cu-BHT and (d) graphene monolayers, simulated with and without the vdW functional.

is mainly contributed by the $\mathrm{S}$ content and promotes the binding of $\mathrm{S}_{8}, \mathrm{Al}_{2} \mathrm{~S}_{18}$, and $\mathrm{Al}_{2} \mathrm{~S}_{12}$, whereas for the lower order $\mathrm{Al}_{2} \mathrm{~S}_{6}$ and $\mathrm{Al}_{2} \mathrm{~S}_{3}$, chemisorption also starts to contribute. For the case of graphene, the contributions from the vdW functional do not change the nature of interactions of $\mathrm{S}_{8}$ and $\mathrm{Al}_{2} \mathrm{~S}_{x}$ (Fig. 2d), other than by decreasing the binding distance values from 3.31-4.34 $\AA$ to 3.17-3.83 A. However, the overall binding energies remain quite constant for graphene throughout the charge/discharge process. On the other hand, for the Cu-BHT MOF, physisorption plays a major role for $\mathrm{S}_{8}$ and the higher order $\mathrm{Al}$ polysulfides $\left(\mathrm{Al}_{2} \mathrm{~S}_{12}\right.$ and $\mathrm{Al}_{2} \mathrm{~S}_{18}$ ) with the range of $84-85 \%$, but for $\mathrm{Al}_{2} \mathrm{~S}_{6}$ and $\mathrm{Al}_{2} \mathrm{~S}_{3}$, chemisorption dominates, having a vdW ratio of 46 and $21 \%$, respectively. The higher contribution of the chemical interaction for the cases of $\mathrm{Al}_{2} \mathrm{~S}_{3}$ and $\mathrm{Al}_{2} \mathrm{~S}_{6}$ can also be clearly understood from Fig. 2c, where $\mathrm{Al}-\mathrm{S}_{\mathrm{Cu}-\mathrm{BHT}}$ and $\mathrm{Cu}-\mathrm{S}_{\mathrm{M}}$ bond formations are observed both with and without inclusion of the vdW functional.

To get more insights into the interaction mechanism between the $\mathrm{Cu}$-BHT MOF and Al polysulfides, we have analysed 
the charge density difference $\left(\rho_{\mathrm{CDD}}\right)$, as expressed by the following equation:

$$
\rho_{\mathrm{CDD}}=\rho^{\text {total }}-\sum_{i} \rho_{i}^{\text {fragments }}
$$

where $\rho^{\text {total }}$ is the total charge density of the system and $\rho_{i}^{\text {fragments }}$ is the charge density of the individual fragments that make up the system. Here, the charge density of the fragments $\left(\rho_{i}^{\text {fragments }}\right)$ is calculated by using a pseudo structure in which fragment part retains the same structure as in the total system but the other parts are deleted. The charge density difference plot presented in Fig. 3a clearly shows charge distribution between $\mathrm{Al}_{2} \mathrm{~S}_{x}$ molecules and the Cu-BHT MOF, where the pink and green colours represent charge accumulation and depletion, respectively. The extent of charge transfer follows a general trend of increment from $\mathrm{Al}_{2} \mathrm{~S}_{18}$ to $\mathrm{Al}_{2} \mathrm{~S}_{3}$, but it is lowest for the $\mathrm{Al}_{2} \mathrm{~S}_{12}$ system, which is in accordance with the binding energy values (Fig. 2a). The higher charge exchange between $\mathrm{Al}_{2} \mathrm{~S}_{3}$ and the
Cu-BHT MOF indicates the involvement of strong chemical interactions, which decrease as the content of S increases in the higher order $\mathrm{Al}$ polysulfides. Overall, two opposite charge transfer channels, (1) $\mathrm{S}_{\mathrm{Cu}-\mathrm{BHT}}-\mathrm{Al}$ and (2) $\mathrm{S}_{\mathrm{M}}-\mathrm{Cu}$, are contributing to the chemical interactions and the dominance of one of these two charge transfer channels determines the net direction of charge transfer. The quantitative charge transfer values calculated using Bader charge analysis (Table 1) ${ }^{71-74}$ further support the results of the charge density difference analysis, whereby the $\mathrm{Al}_{2} \mathrm{~S}_{12}$ system undergoes 0.05 electronic charge transfer from $\mathrm{Cu}-\mathrm{BHT} \mathrm{MOF}$ to $\mathrm{Al}_{2} \mathrm{~S}_{12}$ molecule. The Bader charge transfer values increase from $\mathrm{Al}_{2} \mathrm{~S}_{18}(0.05|e|)$ to $\mathrm{Al}_{2} \mathrm{~S}_{6}(0.24|e|)$, and to finally $\mathrm{Al}_{2} \mathrm{~S}_{3}(0.73|e|)$, which is in accordance with the binding energy trend and this increased charge transfer is the reason for the improved chemical binding strength. The overall improvement in the binding of the Cu-BHT monolayer with $\mathrm{Al}_{2} \mathrm{~S}_{x}$ molecules can be associated with the probability of $\mathrm{Cu}$ ions having a Lewis acid nature (due to empty $3 d$ orbitals) that enables them to interact with soft Lewis

(a)
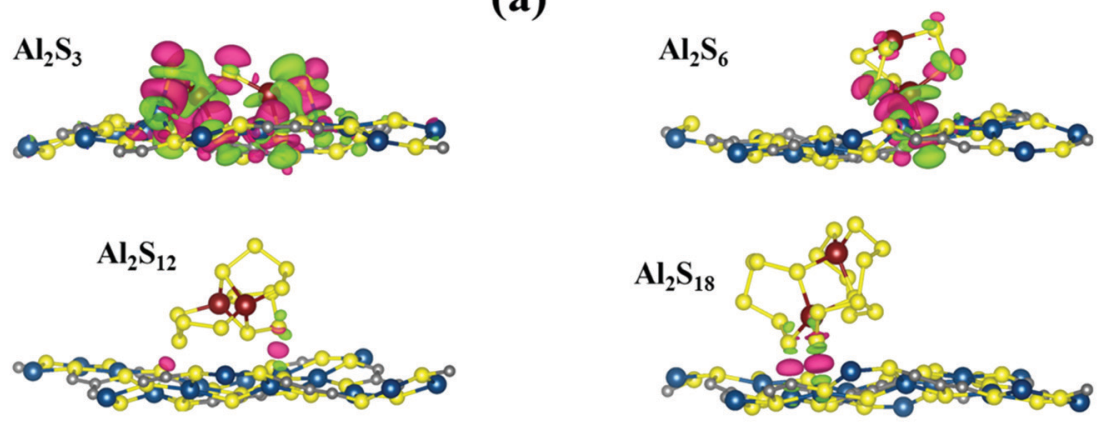

(b)
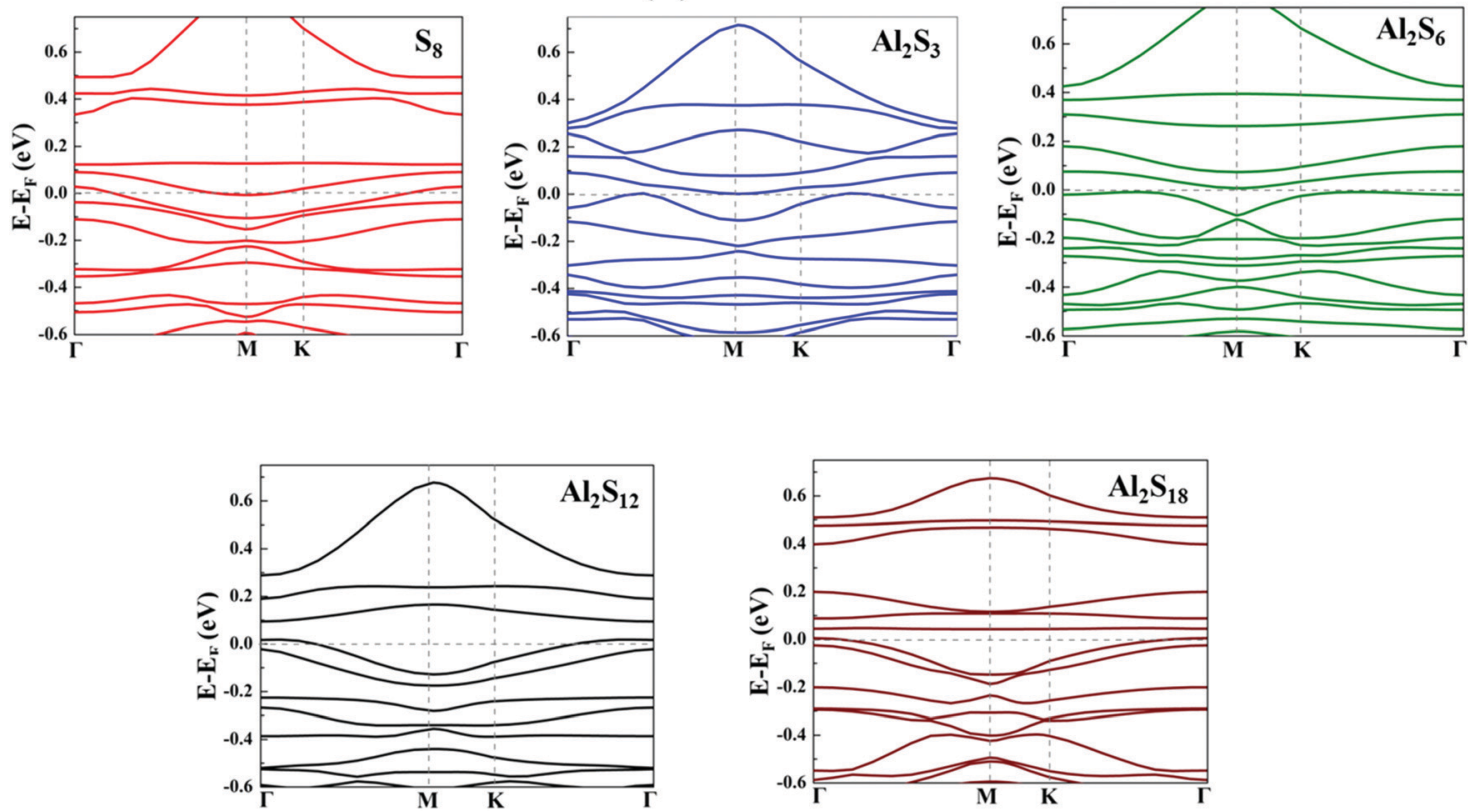

Fig. 3 (a) Charge density difference $\left(\rho_{\mathrm{CDD}}\right)$ plots of $\mathrm{Al}_{2} \mathrm{~S}_{x}$ molecules on the Cu-BHT MOF surface (isosurface value $=0.0015$ e $\AA^{-3}$ ). Here, the pink and green colors represent charge accumulation and depletion, respectively. (b) Electronic band structures of $\mathrm{S}_{8}$ and $\mathrm{Al}_{2} \mathrm{~S}_{x}$ molecules on the Cu-BHT MOF. The Fermi level is set to zero and presented in grey. 
Table 1 Charge transfer between $\mathrm{Al}_{2} \mathrm{~S}_{x}$ molecules and the $\mathrm{Cu}$-BHT MOF. Here, a negative value indicates charge transfer from Cu-BHT MOF to $\mathrm{Al}_{2} \mathrm{~S}_{x}$ molecules

\begin{tabular}{lllll}
\hline System & $\mathrm{Al}_{2} \mathrm{~S}_{18}$ & $\mathrm{Al}_{2} \mathrm{~S}_{12}$ & $\mathrm{Al}_{2} \mathrm{~S}_{6}$ & $\mathrm{Al}_{2} \mathrm{~S}_{3}$ \\
\hline Charge transfer $(|e|)$ & 0.05 & -0.05 & 0.24 & 0.73
\end{tabular}

base $\mathrm{S}_{\mathrm{M}}$ atoms of $\mathrm{Al}_{2} \mathrm{~S}_{x}$ (having electron lone pairs) along with the Lewis base $\mathrm{S}_{\mathrm{Cu}-\mathrm{BHT}}$ being able to strongly interact with $\mathrm{Al}$ cations of the $\mathrm{Al}_{2} \mathrm{~S}_{x}$ molecules.

Further, to evaluate the suitability of the Cu-BHT MOF as a cathode host in Al-S batteries, it is important to check whether it is able to overcome the insulating nature of the $\mathrm{S}$ cathode and the corresponding $\mathrm{Al}$ polysulfides formed during charging and discharging processes to provide constant conductivity in the system. Cu-BHT is superconducting in nature with $T_{\mathrm{c}} \sim 3 \mathrm{~K}^{75}$ Fig. $3 \mathrm{~b}$ shows the electronic band structures of the $\mathrm{S}_{8}$ and $\mathrm{Al}_{2} \mathrm{~S}_{x}$ containing $\mathrm{Cu}$-BHT monolayer systems. All the systems retain their metallic character in the presence of the Cu-BHT monolayer. We further observed that for all $\mathrm{S}_{8}$ and $\mathrm{Al}_{2} \mathrm{~S}_{x}$ containing $\mathrm{Cu}$-BHT MOF systems except the case of $\mathrm{Al}_{2} \mathrm{~S}_{3}$, the bands at the Fermi level are quite flat, indicating no significant interaction between $\mathrm{S}_{8} / \mathrm{Al}_{2} \mathrm{~S}_{x}$ and Cu-BHT MOF. Moreover, for the $\mathrm{Al}_{2} \mathrm{~S}_{3}$ system along the high symmetry $k$-point path, from $\Gamma$ point to $K$ point, the nature of the bands at the Fermi level is not flat. And, this further signifies the strong interaction between $\mathrm{Al}_{2} \mathrm{~S}_{3}$ and the Cu-BHT MOF as observed from the binding energy and charge transfer calculations. This metallic nature may be suitable to provide electron conduction in the whole system, making a path for electrons to participate in the redox reactions of $\mathrm{S}_{8}$ and $\mathrm{Al}$ polysulfides on the $\mathrm{Cu}-\mathrm{BHT}$ surface during charge/ discharge reactions. Therefore, the Cu-BHT system may work in a similar manner to the experimentally studied S@HKUST-1-C system, ${ }^{48}$ where a significant decrease in the kinetic barrier for the conversion of sulfur species during battery operation is observed due to the presence of $\mathrm{Cu}$ atoms.

The strong interaction between $\mathrm{Al}_{2} \mathrm{~S}_{3}$ and $\mathrm{Cu}-\mathrm{BHT}$ may not be good for the performance of the Al-S battery as it can lead to decomposition of $\mathrm{Al}_{2} \mathrm{~S}_{3}$ and reduce the reversibility of the charging process. Therefore, to check the possibility of $\mathrm{Al}_{2} \mathrm{~S}_{3}$ decomposition on the Cu-BHT surface, we calculated the binding energy difference between the intact and decomposed structures. The following decomposition reactions were studied:

$$
\begin{gathered}
\mathrm{Al}_{2} \mathrm{~S}_{3} \rightarrow \mathrm{Al}+\mathrm{AlS}_{3} ; \Delta E_{1}=E_{\mathrm{Al}_{2} \mathrm{~S}_{3}}-E_{\mathrm{Al}_{+} \mathrm{AlS}_{3}}=-0.21 \mathrm{eV} \\
\mathrm{Al}_{2} \mathrm{~S}_{3} \rightarrow \mathrm{Al}+\mathrm{Al}+\mathrm{S}_{3} ; \Delta E_{2}=E_{\mathrm{Al}_{2} \mathrm{~S}_{3}}-E_{\mathrm{Al}+\mathrm{Al}+\mathrm{S}_{3}}=-0.11 \mathrm{eV}
\end{gathered}
$$

where $\Delta E_{1}$ and $\Delta E_{2}$ are the binding energy differences for the decomposition reactions (8) and (9). The optimized conformations are shown in Fig. S2, ESI. $\dagger$ We observed that for both decomposition possibilities, the binding energy differences, $\Delta E_{1}$ and $\Delta E_{2}$, have negative values, suggesting the higher stability of $\mathrm{Al}_{2} \mathrm{~S}_{3}$ compared to its decomposed configurations. This suggests that even though $\mathrm{Al}_{2} \mathrm{~S}_{3}$ shows strong binding with the $\mathrm{Cu}$-BHT surface, the possibility of its further decomposition is very small and, therefore, it should not decrease the overall reversibility of the charging process in $\mathrm{Al}-\mathrm{S}$ batteries. However, the strong binding of $\mathrm{Al}_{2} \mathrm{~S}_{3}$ can certainly increase the charging potential for the initial steps involving $\mathrm{Al}_{2} \mathrm{~S}_{3} \rightarrow \mathrm{Al}_{2} \mathrm{~S}_{6}$ interconversion.

\subsection{Interaction with the electrolyte}

One of the primary concerns for sulfur based batteries is the low confinement of elemental sulfur and polysulfides in the cathode host compared to their increased attraction towards the involved electrolyte, which leads to shuttle reactions that cause poor cycle lifetimes, high self-discharge rates and low Coulombic efficiency. In $\mathrm{Al}-\mathrm{S}$ batteries, the carbonaceous cathode host (S@C) is also observed to show pronounced shuttling effects of $\mathrm{Al}$ polysulfides from cathode to anode and fast capacity decay, poor $\mathrm{S}$ utilization, and low reversibility. ${ }^{48}$ We have calculated the binding strengths of higher order $\mathrm{Al}_{2} \mathrm{~S}_{x}$ $(x=6,12$, and 18) with an ionic liquid electrolyte and compared the results for the graphene and Cu-BHT hosts. To take a reliable approach and to uncover the solvation effect, we have employed the bulk liquid electrolyte model (Fig. 4) to calculate the binding energies of $\mathrm{Al}_{2} \mathrm{~S}_{x}$ with the ionic liquid electrolyte. The bulk electrolyte model was constructed using a cubic supercell of $22.58 \AA$ length containing $32 \mathrm{EMIM}^{+} \mathrm{AlCl}_{4}{ }^{-}$ molecules consistent with the density of about $1.3 \mathrm{~g} \mathrm{~cm}^{-3}$ $\mathrm{EMIM}^{+} \mathrm{AlCl}_{4}{ }^{-}$electrolyte. For simulation of the higher order polysulfides, $\mathrm{Al}_{2} \mathrm{~S}_{6} / \mathrm{Al}_{2} \mathrm{~S}_{12}$ and $\mathrm{Al}_{2} \mathrm{~S}_{18}$, the cubic supercell contained $31 \mathrm{EMIM}^{+} \mathrm{AlCl}_{4}{ }^{-}$with $1 \mathrm{Al}_{2} \mathrm{~S}_{6} / \mathrm{Al}_{2} \mathrm{~S}_{12}$ and 30 $\mathrm{EMIM}^{+} \mathrm{AlCl}_{4}{ }^{-}$with $1 \mathrm{Al}_{2} \mathrm{~S}_{18}$, respectively. We allowed the AIMD simulation to run for $2 \mathrm{ps}$ with the NVT ensemble at $300 \mathrm{~K}$ and the Nose thermostat ${ }^{76}$ was used to control the temperature. The corresponding total energy vs. time plots are shown in Fig. S4, $\mathrm{ESI}, \dagger$ and the resultant bulk systems obtained after 2 ps are presented in Fig. 4.

The last 1 ps of simulation was used to calculate the average total energy of the simulated bulk systems (Fig. 4a-d). The average binding energy for each system was obtained using the following equation:

$$
E_{\text {Binding }}=\left(E_{\text {Elecrolyte+M }}-E_{\text {Electrolyte }}-E_{\mathrm{M}}\right)
$$

where $E_{\text {Elecrolyte+M }}$, and $E_{\text {Electrolyte }}$ are the average total energy of the bulk electrolyte system with and without $\mathrm{Al}_{2} \mathrm{~S}_{x}$ molecules, respectively. $E_{\mathrm{M}}$ is the total energy of an isolated $\mathrm{Al}_{2} \mathrm{~S}_{x}$ molecule. The binding energy of the $\mathrm{Al}$ polysulfides with the $\mathrm{EMIM}^{+} \mathrm{AlCl}_{4}{ }^{-}$ electrolyte increases from $\mathrm{Al}_{2} \mathrm{~S}_{6}$ to $\mathrm{Al}_{2} \mathrm{~S}_{12}$, which is in accordance with the experimental observations, where the higher order Al polysulfides, $\mathrm{S}_{x}{ }^{2-}, x \geq 6$, were found to be soluble in ionic liquid electrolyte. A comparison of the binding energies of higher order polysulfides with the graphene/Cu-BHT hosts and the electrolyte is given in Fig. 4e.

We observed that the $\mathrm{EMIM}^{+} \mathrm{AlCl}_{4}{ }^{-}$ionic liquid electrolyte shows a higher binding strength for $\mathrm{Al}_{2} \mathrm{~S}_{18}(-1.49 \mathrm{eV}), \mathrm{Al}_{2} \mathrm{~S}_{12}$ $(-1.34 \mathrm{eV})$ and $\mathrm{Al}_{2} \mathrm{~S}_{6}(-1.11 \mathrm{eV})$ compared to the graphene monolayer $(-0.84$ to $-0.87 \mathrm{eV})$. Moreover, we also observed that the electrolyte itself shows stronger binding to the graphene surface with the binding energy of $-0.95 \mathrm{eV}$, much higher than 
(a)

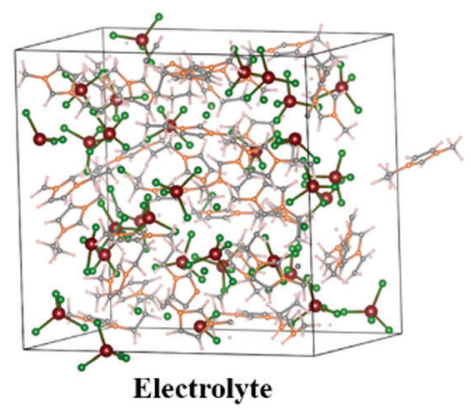

(d)

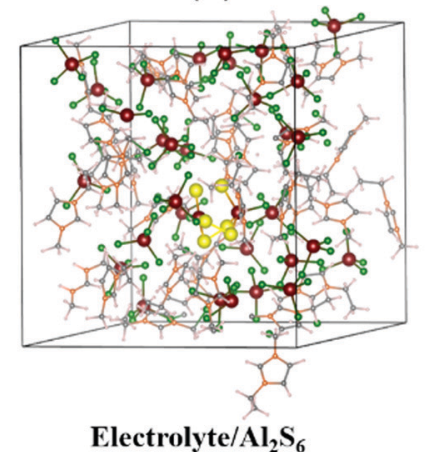

(b)

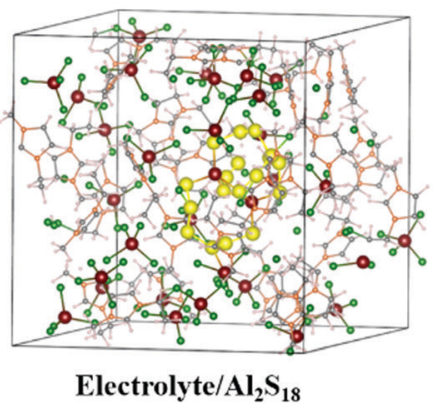

(c)

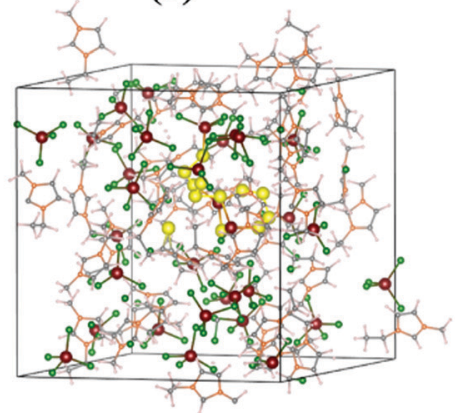

Electrolyte/ $/ \mathrm{Al}_{2} \mathrm{~S}_{12}$

(e)

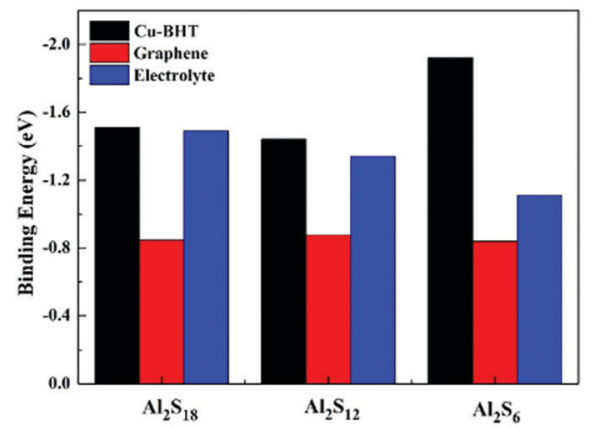

Fig. 4 Optimized supercells of (a) $\mathrm{EMIM}^{+} \mathrm{AlCl}_{4}^{-}$electrolyte, (b) $\mathrm{EIM}^{+} \mathrm{AlCl}_{4}^{-} / \mathrm{Al}_{2} \mathrm{~S}_{18}$, (c) $\mathrm{EMIM}^{+} \mathrm{AlCl}_{4}^{-} / \mathrm{Al}_{2} \mathrm{~S}_{12}$, and (d) $\mathrm{EMIM}^{+} \mathrm{AlCl}_{4}{ }^{-} / \mathrm{Al}_{2} \mathrm{~S}_{6}$ after 2 ps of $\mathrm{AIMD}$ simulations. $\mathrm{Al}_{2} \mathrm{~S}_{18}, \mathrm{Al}_{2} \mathrm{~S}_{12}$, and $\mathrm{Al}_{2} \mathrm{~S}_{6}$ immersed in an ionic liquid are highlighted by larger spheres. (d) Comparative binding energies of $\mathrm{Al}_{2} \mathrm{~S}_{x}(x=6,12$, and 18$)$ molecules with graphene, the $\mathrm{Cu}-\mathrm{BHT}$ monolayer and $\mathrm{EMIM}^{+} \mathrm{AlCl}_{4}{ }^{-}$electrolyte.

those of $\mathrm{S}_{8}$ and $\mathrm{Al}_{2} \mathrm{~S}_{x}$ molecules on graphene. Based on these results, we can conclude that carbonaceous materials do not make suitable anchoring hosts for Al-S batteries, as they not only are able to bind elemental sulfur and Al-polysulfides strongly, but the involved ionic liquid electrolyte also competes to bind with the carbonaceous host. And, all of these reasons lead to shutting effects of intermediate polysulfides, observed in experimental applications of carbon-based cathode hosts. ${ }^{48}$

However, in the case of the Cu-BHT monolayer, even after consideration of the solvation effect in the bulk electrolyte environment, the binding energies of Al polysulfides $(-1.51$ to $-1.92 \mathrm{eV}$ ) on the Cu-BHT host are higher than that of the electrolyte. The stronger binding is a result of soft acid-base interactions between the $\mathrm{S}$ atoms (Lewis base) of Al polysulfides and $\mathrm{Cu}(\mathrm{I})$ atoms (Lewis acid) of the Cu-BHT MOF compared to the $\mathrm{Cl}$ atoms of the $\mathrm{EMIM}^{+} \mathrm{AlCl}_{4}{ }^{-}$electrolyte. In addition, the $\mathrm{EMIM}^{+} \mathrm{AlCl}_{4}{ }^{-}$electrolyte was also observed to have a lower interaction energy $(-0.98 \mathrm{eV})$ with the Cu-BHT monolayer host in comparison with the $\mathrm{Al}$ polysulfides. Therefore, there is a lower probability of $\mathrm{S}_{8}$ and $\mathrm{Al}_{2} \mathrm{~S}_{x}$ molecules dissolving in the electrolyte. We expect that the Cu-BHT MOF can act as a potential anchoring host with reduced polysulfide shuttling compared to carbonaceous hosts to provide an improved cycle life in $\mathrm{Al}-\mathrm{S}$ batteries. In a similar way, the vital effect of $\mathrm{Cu}$ has also been observed in a recent experimental report on a HKUST-1-C/S cathode for Al-S batteries, ${ }^{48}$ where, in the electrochemical process,
$\mathrm{Cu}$ forms an ionic cluster with the polysulfide, facilitates the electrochemical reaction and shows improved reversibility of $\mathrm{S}$ cathode during charging/discharging process.

\subsection{Deposition of $\mathrm{Al}_{2} \mathrm{~S}_{3}$ on the Cu-BHT monolayer surface}

Several experimental and theoretical reports on $\mathrm{Li}-\mathrm{S}$ batteries have expressed that a cathode host material able to regulate uniform deposition of the discharge product $\mathrm{Li}_{2} \mathrm{~S}$ is useful to reduce the cell resistance as well as manifest a rapid kinetics in the redox reaction of Li polysulfides. ${ }^{68,77,78}$ Therefore, to check the suitability of $\mathrm{Cu}-\mathrm{BHT}$ as an anchoring material in Al-S batteries, we investigated the deposition behaviour of $\mathrm{Al}_{2} \mathrm{~S}_{3}$ molecules on the Cu-BHT monolayer surface. We compared the binding energies of various possible initial configurations of two and then three $\mathrm{Al}_{2} \mathrm{~S}_{3}$ molecules on the surface of the Cu-BHT MOF. Fig. 5 shows the most stable configurations of the isolated $\mathrm{Al}_{2} \mathrm{~S}_{3}$ molecules and the agglomeration networks for both two and three $\mathrm{Al}_{2} \mathrm{~S}_{3}$ molecule depositions. The relative energies of these configurations show that $\mathrm{Al}_{2} \mathrm{~S}_{3}$ molecules are more inclined to form an agglomerated network and the network size further increases as more $\mathrm{Al}_{2} \mathrm{~S}_{3}$ molecules are deposited on the Cu-BHT surface (Fig. 5c). This uniform deposition of $\mathrm{Al}_{2} \mathrm{~S}_{3}$ on the $\mathrm{Cu}-\mathrm{BHT}$ MOF is a result of the synergistic dual interactions of $\mathrm{Al}-\mathrm{S}_{\mathrm{Cu}-\mathrm{BHT}}$ and $\mathrm{Cu}-\mathrm{S}_{\mathrm{M}}$, which enhance the tendency of $\mathrm{Cu}-\mathrm{BHT}$ to form an electrical contact with $\mathrm{Al}_{2} \mathrm{~S}_{x}$. And, as a result, $\mathrm{Cu}-\mathrm{BHT}$ can reduce the kinetic 

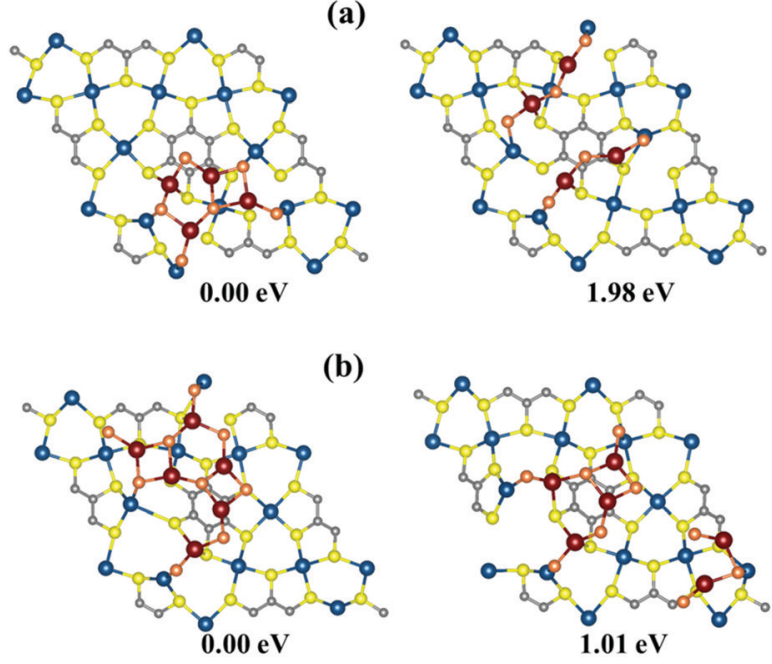

(c)

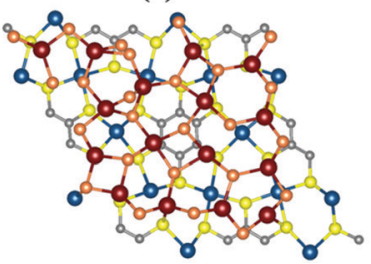

(d)

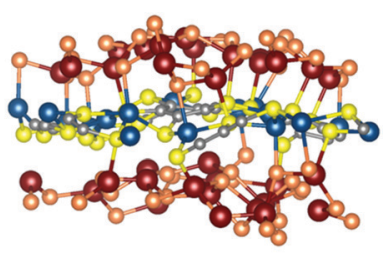

Fig. 5 Optimized configurations of (a) two $\mathrm{Al}_{2} \mathrm{~S}_{3}$ and (b) three $\mathrm{Al}_{2} \mathrm{~S}_{3}$ molecules on the $\mathrm{Cu}-\mathrm{BHT}$ monolayer with their relative energies, situated near and far from each other. (c) Uniform $\mathrm{Al}_{2} \mathrm{~S}_{3}$ layer deposition on the $\mathrm{Cu}-\mathrm{BHT}$ monolayer surface. (d) Side view of the optimized configuration with the maximum stable loading of $\mathrm{Al}_{2} \mathrm{~S}_{3}$ molecules on the $\mathrm{Cu}-\mathrm{BHT}$ monolayer surface. Here, for clear understanding, the sulfur atoms of the $\mathrm{Al}_{2} \mathrm{~S}_{3}$ molecules and the $\mathrm{Cu}-\mathrm{BHT}$ monolayer surface are shown in orange and yellow colors, respectively.

barrier of $\mathrm{Al}$ polysulfide redox reactions. Moreover, this uniform deposition of $\mathrm{Al}_{2} \mathrm{~S}_{3}$ increases the surface utilization of the $\mathrm{Cu}-\mathrm{BHT}$ monolayer, as shown in Fig. 5c.

Further, to check the capacity retention in an Al-S battery, we calculated the amount of sulfur that can be incorporated into the $\mathrm{Cu}$-BHT MOF host. $\mathrm{Al}_{2} \mathrm{~S}_{3}$ molecules were allowed to bind on both sides of a $2 \times 2 \times 1 \mathrm{Cu}$-BHT monolayer to form an energetically stable system. We observed that the $\mathrm{Al}_{2} \mathrm{~S}_{3}$ molecules bind in a layered framework on both sides of the Cu-BHT monolayer (Fig. 5c and d) with average binding energies of $-5.36 \mathrm{eV}$ and $-5.18 \mathrm{eV}$ for one side and both sides of $\mathrm{Cu}-\mathrm{BHT}$, respectively. Upon allowing the binding of a third layer of $\mathrm{Al}_{2} \mathrm{~S}_{3}$ molecules, the system becomes energetically unstable, favouring the binding of $16 \mathrm{Al}_{2} \mathrm{~S}_{3}$ molecules in the $2 \times 2 \times 1 \mathrm{Cu}-\mathrm{BHT}$ monolayer host. Therefore, the maximum amount of sulfur that can be incorporated into the $\mathrm{Cu}-\mathrm{BHT}$ monolayer is 45.81 weight percent (wt\%). The capacity of the Cu-BHT MOF is quite a lot higher than that of the experimentally studied S@HKUST-1-C host, which holds 34 wt $\%$ sulfur. ${ }^{48}$ However, the sulfur capacity of the Cu-BHT MOF reduces for multi-layered systems due to a decrease in the number of exposed sites for $\mathrm{Al}_{2} \mathrm{~S}_{3}$ binding. The $2 \times 2 \times 2$ bilayer and $2 \times 2 \times 3$ trilayer Cu-BHT hosts were observed to hold $38.80 \mathrm{wt} \%$ and $36.00 \mathrm{wt} \%$ sulfur with the average binding energies of $-4.98 \mathrm{eV}$ and $-4.65 \mathrm{eV}$, respectively (Fig. S5, ESI $\dagger$ ).

Overall, for both HKUST and Cu-BHT MOFs, the structure along with the presence of $\mathrm{Cu}$ plays quite an important role in the Al-S battery by enhancing the stability of sulfur and $\mathrm{Al}_{2} \mathrm{~S}_{x}$ molecules, and improving reaction reversibility and electronic conductivity. The Cu-BHT monolayer MOF may work as a more suitable cathode host for $\mathrm{Al}-\mathrm{S}$ batteries, furnishing a higher sulfur capacity.

\section{Conclusion}

In this work, we have investigated the preferential applicability of a 2D Cu-benzenehexathial (Cu-BHT) metal organic framework for use as a potential anchoring cathode host for $\mathrm{Al}-\mathrm{S}$ batteries as compared to a carbonaceous host such as graphene. We observed that the favourable electrical conductivity of the Cu-BHT MOF eliminates the insulating nature of $\mathrm{S}_{8}$ and other $\mathrm{Al}$ polysulfide $\left(\mathrm{Al}_{2} \mathrm{~S}_{x}\right)$ molecules and could be helpful in supporting the cathode charge/discharge processes. From the binding calculations of $\mathrm{S}_{8}$ and $\mathrm{Al}_{2} \mathrm{~S}_{x}$ molecules, we observed that graphene shows consistently low binding energies, where physisorption dominates throughout the whole process of binding (78-87\%). Whereas, the Cu-BHT MOF exhibits improved binding of $\mathrm{Al}$ polysulfides $(-1.44$ to $-3.56 \mathrm{eV})$, because of the presence of copper and sulfur, which results in increased charge transfer to the $\mathrm{Al}$ polysulfides. Moreover, from the comparative study of $\mathrm{S}_{8}$ and $\mathrm{Al}_{2} \mathrm{~S}_{x}$ molecules binding with graphene, Cu-BHT and $\mathrm{EMIM}^{+} \mathrm{AlCl}_{4}{ }^{-}$electrolyte, we concluded that with the relatively stronger binding of $\mathrm{Al}_{2} \mathrm{~S}_{x}$ molecules, an Al-S battery with a Cu-BHT MOF host cathode could show reduced overall dissolution of $\mathrm{Al}$ polysulfides into the electrolyte compared with the case of a carbonaceous host to provide an improved cycle life. The Cu-BHT MOF permits synergic dual interaction based on the Al-S (of the sulfur host) bond and $\mathrm{S}$ (of the Al polysulfide)-Cu bond, leading to the uniform deposition of insoluble $\mathrm{Al}_{2} \mathrm{~S}_{3}$ over the Cu-BHT surface. This improves the utilization of the active cathode host, allowing a better sulfur incorporation of 45.81 wt\% sulfur in the Cu-BHT MOF host, which is even higher compared to the HKUST MOF (34 wt\%) studied in a very recent experimental report. Overall, all of these results suggest that the $\mathrm{Cu}-\mathrm{BHT}$ MOF can be used as a promising anchoring cathode host compared to graphene in $\mathrm{Al}-\mathrm{S}$ batteries.

\section{Conflicts of interest}

There are no conflicts to declare.

\section{Acknowledgements}

We thank IIT Indore for providing the lab and computing facilities. This work is supported by DST-SERB (Project Number CRG/2018/ 001131) and SPARC (Project Number SPARC/2018-2019/P116/SL), New Delhi. P. B. thanks MHRD for a research fellowship. 


\section{References}

1 G. A. Elia, K. Marquardt, K. Hoeppner, S. Fantini, R. Lin, E. Knipping, W. Peters, J.-F. Drillet, S. Passerini and R. Hahn, Adv. Mater., 2016, 28, 7564-7579.

2 Y. Wang, R. Chen, T. Chen, H. Lv, G. Zhu, L. Ma, C. Wang, Z. Jin and J. Liu, Energy Storage Mater., 2016, 4, 103-129.

3 W. I. A. Sadat and L. A. Archer, Sci. Adv., 2016, 2, e1600968. 4 L. Bai, J. Electrochem. Soc., 1990, 137, 3737.

5 P. V. Suneesh, T. G. Satheesh Babu and T. Ramachandran, Int. J. Miner., Metall. Mater., 2013, 20, 909-916.

6 W. Wang, B. Jiang, W. Xiong, H. Sun, Z. Lin, L. Hu, J. Tu, J. Hou, H. Zhu and S. Jiao, Sci. Rep., 2013, 3, 3383.

7 M. Chiku, H. Takeda, S. Matsumura, E. Higuchi and H. Inoue, ACS Appl. Mater. Interfaces, 2015, 7, 24385-24389.

8 H. Wang, Y. Bai, S. Chen, X. Luo, C. Wu, F. Wu, J. Lu and K. Amine, ACS Appl. Mater. Interfaces, 2015, 7, 80-84.

9 H. Wang, X. Bi, Y. Bai, C. Wu, S. Gu, S. Chen, F. Wu, K. Amine and J. Lu, Adv. Energy Mater., 2017, 7, 1602720.

10 J. Jiang, H. Li, J. Huang, K. Li, J. Zeng, Y. Yang, J. Li, Y. Wang, J. Wang and J. Zhao, ACS Appl. Mater. Interfaces, 2017, 9, 28486-28494.

11 W. Kaveevivitchai, A. Huq, S. Wang, M. J. Park and A. Manthiram, Small, 2017, 13, 1701296.

12 L. Mei, J. Xu, Z. Wei, H. Liu, Y. Li, J. Ma and S. Dou, Small, 2017, 13, 1701441.

13 Z. Li, B. Niu, J. Liu, J. Li and F. Kang, ACS Appl. Mater. Interfaces, 2018, 10, 9451-9459.

14 L. Geng, J. P. Scheifers, C. Fu, J. Zhang, B. P. T. Fokwa and J. Guo, ACS Appl. Mater. Interfaces, 2017, 9, 21251-21257.

15 M. A. Vahid, A. Hadjikhani, S. Shahbazmohamadi and M. Beidaghi, ACS Nano, 2017, 11, 11135-11144.

16 S. Liu, J. J. Hu, N. F. Yan, G. L. Pan, G. R. Li and X. P. Gao, Energy Environ. Sci., 2012, 5, 9743-9746.

17 M. C. Lin, M. Gong, B. Lu, Y. Wu, D. Y. Wang, M. Guan, M. Angell, C. Chen, J. Yang, B. J. Hwang and H. Dai, Nature, 2015, 520, 324-328.

18 K. V. Kravchyk, S. Wang, L. Piveteau and M. V. Kovalenko, Chem. Mater., 2017, 29, 4484-4492.

19 P. Bhauriyal, A. Mahata and B. Pathak, Phys. Chem. Chem. Phys., 2017, 19, 7980-7989.

20 S. Wang, K. V. Kravchyk, F. Krumeich and M. V. Kovalenko, ACS Appl. Mater. Interfaces, 2017, 9, 28478-28485.

21 N. P. Stadie, S. Wang, K. V. Kravchyk and M. V. Kovalenko, ACS Nano, 2017, 11, 1911-1919.

22 A. S. Childress, P. Parajuli, J. Zhu, R. Podila and A. M. Rao, Nano Energy, 2017, 39, 69-76.

23 H. Chen, H. Xu, S. Wang, T. Huang, J. Xi, S. Cai, F. Guo, Z. Xu, W. Gao and C. Gao, Sci. Adv., 2017, 3, eaao7233.

24 H. Chen, F. Guo, Y. Liu, T. Huang, B. Zheng, N. Ananth, Z. Xu, W. Gao and C. Gao, Adv. Mater., 2017, 29, 1605958.

25 Y. Wu, M. Gong, M.-C. Lin, C. Yuan, M. Angell, L. Huang, D.-Y. Wang, X. Zhang, J. Yang and B.-J. Hwang, et al., Adv. Mater., 2016, 28, 9218-9222.

26 P. Bhauriyal, A. Mahata and B. Pathak, J. Phys. Chem. C, 2017, 121, 9748-9756.
27 P. Bhauriyal, A. Mahata and B. Pathak, Chem. - Asian J., 2017, 12, 1944-1951.

28 P. Bhauriyal, P. Garg, M. Patel and B. Pathak, J. Mater. Chem. A, 2018, 6, 10776-10786.

29 P. Bhauriyal, G. Bhattacharyya, K. S. Rawat and B. Pathak, J. Phys. Chem. C, 2019, 123, 3959-3967.

30 N. S. Hudak, J. Phys. Chem. C, 2014, 118, 5203-5215.

31 Z. A. Zafar, S. Imtiaz, R. Razaq, S. Ji, T. Huang, Z. Zhang, Y. Huang and J. A. Anderson, J. Mater. Chem. A, 2017, 5, 5646-5660.

32 T. Mori, Y. Orikasa, K. Nakanishi, C. Kezheng, M. Hattori, T. Ohta and Y. Uchimoto, J. Power Sources, 2016, 313, 9-14.

33 S. Wang, Z. Yu, J. Tu, J. Wang, D. Tian, Y. Liu and S. Jiao, Adv. Energy Mater., 2016, 6, 1600137.

34 Z. Yu, Z. Kang, Z. Hu, J. Lu, Z. Zhou and S. Jiao, Chem. Commun., 2016, 52, 10427-10430.

35 S. Wang, S. Jiao, J. Wang, H.-S. Chen, D. Tian, H. Leia and D.-N. Fang, ACS Nano, 2017, 11, 469-477.

36 A. Manthiram, Y. Fu, S.-H. Chung, C. Zua and Y.-S. Su, Chem. Rev., 2014, 114, 11751-11787.

37 A. Manthiram, Y. Fu and Y.-S. Su, Acc. Chem. Res., 2013, 46, 1125-1134.

38 M. J. Klein, G. M. Veith and A. Manthiram, J. Am. Chem. Soc., 2017, 139, 10669-10676.

39 Q. Pang, X. Liang, C. Y. Kwok and F. N. Nazar, Nat. Energy, 2016, 1, 16132.

40 S. Xin, Y.-X. Yin, Y.-G. Guo and L.-J. Wan, Adv. Mater., 2014, 26, 1261-1265.

41 S. Wenzel, H. Metelmann, C. Raiß, A. K. Dürr, J. Janek and P. Adelhelm,, J. Power Sources, 2013, 243, 758-765.

42 T. Gao, M. Noked, A. J. Pearse, E. Gillette, X. Fan, Y. Zhu, C. Luo, L. Suo, M. A. Schroeder and K. Xu, et al., J. Am. Chem. Soc., 2015, 137, 12388-12393.

43 W. Li, S. Cheng, J. Wang, Y. Qiu, Z. Zheng, H. Lin, S. Nanda, Q. Ma, Y. Xu, F. Ye, M. Liu, L. Zhou and Y. Zhang, Angew. Chem., Int. Ed., 2016, 55, 6406.

44 G. Cohn, L. Ma and L. A. Archer, J. Power Sources, 2015, 283, 416-422.

45 T. Gao, X. Li, X. Wang, J. Hu, F. Han, X. Fan, L. Suo, A. J. Pearse, S. B. Lee, G. W. Rubloff, K. J. Gaskell, M. Noked and C. Wang, Angew. Chem., Int. Ed., 2016, 55, 9898-9901 (Angew. Chem., Int. Ed., 128, 10052-10055).

46 X. Yu and A. Manthiram, Adv. Energy Mater., 2017, 7, 1700561. 47 X. Yu, M. J. Boyer, G. S. Hwang and A. Manthiram, Chem, 2018, 4, 586-598.

48 Y. Guo, H. Jin, Z. Qi, Z. Hu, H. Ji and L.-J. Wan, Adv. Funct. Mater., 2019, 29, 1807676.

49 P. Bhauriyal, S. Das and B. Pathak, J. Phys. Chem. C, 2020, 124, 11317-11324.

50 Z. Wang, B. Wang, Y. Yang, Y. Cui, Z. Wang, B. Chen and G. Qian, ACS Appl. Mater. Interfaces, 2015, 7, 20999-21004.

51 G.-P. Hao, C. Tang, E. Zhang, P.-Y. Zhai, J. Yin, W. Zhu, Q. Zhang and S. Kaskel, Adv. Mater., 2017, 29, 1702829.

52 Y. Mao, G. Li, Y. Guo, Z. Li, C. Liang, X. Peng and Z. Lin, Nat. Commun., 2017, 8, 14628.

53 J. Zhou, R. Li, X. Fan, Y. Chen, R. Han, W. Li, J. Zheng, B. Wang and X. Li, Energy Environ. Sci., 2014, 7, 2715-2724. 
54 X. Huang, P. Sheng, Z. Tu, F. Zhang, J. Wang, H. Geng, Y. Zou, C.-an. Di, Y. Yi, Y. Sun, W. Xu and D. Zhu, Nat. Commun., 2015, 6, 7408.

55 G. Kresse and J. Hafner, Phys. Rev. B: Condens. Matter Mater. Phys., 1993, 47, 558.

56 G. Kresse and J. Hafner, Phys. Rev. B: Condens. Matter Mater. Phys., 1994, 49, 14251.

57 G. Kresse and J. Furthmüller, Comput. Mater. Sci., 1996, 6, 15-50.

58 G. Kresse and J. Furthmüller, Phys. Rev. B: Condens. Matter Mater. Phys., 1996, 54, 11169-11186.

59 J. P. Perdew, K. Burke and M. Ernzerhof, Phys. Rev. Lett., 1996, 77, 3865-3868.

60 J. P. Perdew, K. Burke and M. Ernzerhof, Phys. Rev. Lett., 1997, 78, 1396.

61 P. E. BlÖchl, Phys. Rev. B: Condens. Matter Mater. Phys., 1994, 50, 1795-17979.

62 G. Kresse and D. Joubert, Phys. Rev. B: Condens. Matter Mater. Phys., 1999, 59, 1758.

63 S. Grimme, J. Antony, S. Ehrlich and H. Krieg, J. Chem. Phys., 2010, 132, 154104.

64 E. D. Jemmis, K. T. Giju and J. Leszczynski, J. Theor. Chem., 1997, 2, 130-138.

65 N. Zhang, Y. Shi, Z. Gao, F. Kong and Q. Zhu, J. Chem. Phys., 1994, 101, 1219.
66 T. Yu, F. Li, C. Liu, S. Zhang, H. Xu and G. Yang, J. Mater. Chem. A, 2017, 5, 9293-9298.

67 X. Zhang, Y. Zhou, B. Cui, M. Zhao and F. Liu, Nano Lett., 2017, 17, 6166-6170.

68 F. Li, X. Zhang, X. Liu and M. Zhao, ACS Appl. Mater. Interfaces, 2018, 10, 15012-15020.

69 Y. X. Zhao and I. L. Spain, Phys. Rev. B: Condens. Matter Mater. Phys., 1989, 40, 993.

70 A. Bosak, M. Krisch, M. Mohr, J. Maultzsch and C. Thomsen, Phys. Rev. B: Condens. Matter Mater. Phys., 2007, 75, 153408.

71 R. F. W. Bader, Chem. Rev., 1991, 91, 893-928.

72 G. Henkelman, A. Arnaldsson and H. Jonsson, Comput. Mater. Sci., 2006, 36, 354-360.

73 E. Sanville, S. D. Kenny, R. Smith and G. J. Henkelman, J. Comput. Chem., 2007, 28, 899-908.

74 W. Tang, E. Sanville and G. J. Henkelman, J. Condens. Matter Phys., 2009, 21, 084204.

75 X. Huang, S. Zhang, L. Liu, L. Yu, G. Chen, W. Xu and D. Zhu, Angew. Chem., Int. Ed., 2018, 57, 146.

76 S. Nosé, A unified formulation of the constant temperature molecular dynamics methods, J. Chem. Phys., 1984, 81, 511.

77 L. Kong, X. Chen, B.-Q. Li, H.-J. Peng, J.-Q. Huang, J. Xie and Q. Zhang, Adv. Mater., 2018, 30, 1705219.

78 J. Zhao, Y. Yang, R. S. Katiyar and Z. Chen, J. Mater. Chem. A, 2016, 4, 6124-6130. 